\title{
Problemas administrativos en los nuevos espacios metropolitanos: la ausencia de una respuesta normativa suficiente en la Comunidad Autónoma de Castilla y León
}

\author{
Ricardo Rivero Ortega \\ Profesor Titular de Derecho Administrativo \\ Universidad de Salamanca
}

\begin{abstract}
Sumario: I. PRESENTACIÓN Y OBJETO DE ESTE TRABAJO. II. EL TRATAMIENTO DE LAS ÁREAS METROPOLITANAS EN NUESTRO DERECHO LOCAL. III. EL RECONOCIMIENTO EN EL LIBRO BLANCO PARA LA REFORMA DEL GOBIERNO LOCAL EN ESPAÑA DE LA PROBLEMÁTICA DE LAS GRANDES ÁREAS URBANAS Y SU ESCASO TRATAMIENTO EN EL BORRADOR DE ANTEPROYECTO DE LEY BÁSICA DEL GOBIERNO Y LA ADMINISTRACIÓN LOCAL. IV. EL DERECHO COMO HERRAMIENTA DE SOLUCIÓN DE PROBLEMAS EN LOS NUEVOS ESPACIOS METROPOLITANOS: EXPERIENCIAS AUTONÓMICAS COMPARADAS Y OTRAS SOLUCIONES INSTITUCIONALES QUE LA NORMATIVA DE RÉGIMEN LOCAL PODRÍA OFRECER. A) La necesidad de la respuesta autonómica a la problemática metropolitana y su corto alcance en el panorama comparado. B) Soluciones institucionales que la normativa de régimen local podría ofrecer: tipología instrumental metropolitana y competencias para su regulación. V. EL CASO DE CASTILLA Y LEÓN: LA ESCASEZ DE LA RESPUESTA NORMATIVA EN LA LEY DE RÉGIMEN LOCAL DE CASTILLA Y LEÓN Y LAS INSUFICIENCIAS DE OTRAS PREVISIONES NORMATIVAS (LEY DE ORDENACIÓN DEL TERRITORIO Y DIRECTRICES DE ORDENACIÓN, LEY DEL TRANSPORTE URBANO Y METROPOLITANO). VI. CRÍTICA CONSTRUCTIVA ANTE LAS PERSPECTIVAS DE NUEVA LEY BÁSICA DE LA ADMINISTRACIÓN Y EL GOBIERNO LOCAL Y LA REFORMA DE LOS ESTATUTOS DE AUTONOMÍA: LA NECESIDAD, EN UN MEDIO PLAZO, DE REFORMAR LA LEY DE RÉGIMEN LOCAL DE CASTILLA Y LEÓN.
\end{abstract}

\section{Presentación y objeto de este trabajo}

Es un honor poder participar en el número 300 de la Revista de Estudios de la Administración Local y Autonómica, por la trayectoria de esta publicación periódica y por su prestigio en el mundo jurídico ${ }^{1}$.

\footnotetext{
${ }^{1}$ Aprovecho la ocasión para agradecer la amable invitación del Director de la Revista, el Catedrático de Derecho Administrativo y Rector de la Universidad de las Islas Baleares, Profesor Doctor Avelino Blasco Esteve. También debo indicar que una parte del texto de este trabajo fue presentado como ponencia en las Jornadas organizadas por el Ayuntamiento de Valladolid sobre «La Reforma del Gobierno Local en España. Reflexiones sobre las propuestas y carencias del Libro Blanco», a las que fui invitado por su Secretario, Don Valentín Merino, a quien extiendo mi agradecimiento.
} 
Además, este volumen especial se publica en un momento importante, aunque sólo uno más, para el desarrollo de las Administraciones locales - también para las Comunidades Autónomas- en nuestro país. Tras la presentación de la versión definitiva del Libro Blanco para la Reforma del Gobierno local en España durante el verano de 2005, se maneja ahora un Borrador de Anteproyecto de Ley Básica del Gobierno y la Administración Local, un texto que no pretende ser una mera modificación, como las últimas importantes (en 1999 y 2003) de la vigente Ley de Bases de 1985, sino que, en la línea de otras reformas promovidas por el Gobierno del Presidente ZAPATERO, intenta reformular el régimen de las entidades locales en España ${ }^{2}$.

En este contexto de reformas actualizadoras, el presente trabajo estará dedicado al análisis de los problemas planteados en los nuevos espacios metropolitanos hoy, especialmente en una Comunidad Autónoma, Castilla y León, cuya realidad municipal distaba de sufrir hasta fechas muy recientes la problemática de las grandes ciudades. No ha sido hasta finales del siglo pasado cuando varias ciudades de la Comunidad, y muy especialmente Valladolid y su entorno, han empezado a reclamar un tratamiento metropolitano ante el espectacular crecimiento urbanístico, no siempre bien ordenado, que están experimentando. Y esta nueva realidad geográfica urbana puede no haber sido suficientemente atendida, por las razones que expondremos, en el ordenamiento autonómico vigente ${ }^{3}$.

Donde los problemas de las grandes áreas urbanas sí son perfectamente reconocidos es en el Libro Blanco para la Reforma del Gobierno local en España, que intenta proponer algunas soluciones a los mismos. Efectivamente, una reforma del régimen local español parece precisa para reconocer nuevas herramientas jurídicas (más flexibles que las previstas y empleadas hasta ahora) adaptadas a la complejidad de las relaciones interadministrativas en los nuevos espacios metropolitanos. Pero esta reforma no pasa principalmente por la legislación básica, sino en gran medida por las leyes autonómicas, dado el reparto constitucional y la evolución del «bloque de la constitucionalidad» en esta materia ${ }^{4}$.

En mi desarrollo argumental, comenzaré con una exposición de la evolución histórica y el régimen actual de las áreas metropolitanas en nuestro ré-

\footnotetext{
${ }^{2}$ Otras reformas totales de leyes administrativas relevantes, en trámite parlamentario o en fase de Anteproyecto, son el Estatuto Básico del empleado público, la Ley de Agencias y la Ley de Contratos del Sector Público. El presente estudio se cierra el 20 de abril de 2006, de manera que es muy probable la aprobación de alguno de estos textos, o de todos ellos, para cuando el número 300 de la REALA vea la luz.

${ }^{3}$ Hay que recordar que la última reforma del Estatuto de Autonomía de Castilla y León se aprueba en 1999. La Ley de Régimen Local de la Comunidad Autónoma es de 1998, y sus leyes de Urbanismo y Ordenación del Territorio de 1998 y 1999, respectivamente.

${ }^{4}$ Vid. García Roca, Javier, «El concepto de autonomía local según el bloque de la constitucionalidad», REALA, núm.282, 2000.
} 
PROBLEMAS ADMINISTRATIVOS EN LOS NUEVOS ESPACIOS METROPOLITANOS

gimen local, hoy representado sobre todo por la Ley de Bases de 1985. Después expondré el diagnóstico del Libro Blanco para la reforma del Gobierno local en España y sus referencias a la problemática específica de las grandes áreas urbanas, apenas tratadas en el Borrador de Anteproyecto de Ley Básica del Gobierno y la Administración Local, al menos en la versión que he manejado, con fecha de 22 de noviembre de 2005.

A continuación, plantearé las soluciones que, desde el Derecho, podrían emplearse para mejorar la intervención administrativa en estos espacios, algunas ya ensayadas en otras Comunidades Autónomas, a pesar del relativo fracaso en el panorama autonómico de la figura del área metropolitana. En el caso de Castilla y León, como mostraré analizando sus principales leyes (Régimen local, Urbanismo, Ordenación del Territorio, Transporte Urbano y Metropolitano), el fenómeno ha sido casi ignorado. Por ello concluiré con algunas reflexiones críticas sobre nuestro actual régimen local, proyectadas sobre el Borrador de Anteproyecto de Ley Básica del Gobierno y la Administración local, pero sobre todo en el ordenamiento local de Castilla y León, que considero necesitado de una importante reforma a medio plazo.

\section{El tratamiento de las áreas metropolitanas en nuestro Dere- cho local}

En la historia de nuestro régimen local se han señalado tempranos antecedentes normativos para responder a la problemática metropolitana: el Proyecto Chaparrieta, de 1923, o el Estatuto Calvo Sotelo, de 1924, con su régimen de Carta. La posterior legislación de Madrid, Bilbao o Valencia, en los años cuarenta, y Barcelona, en los cincuenta, estará marcada, como nos explica Concha BARRERO, por la anexión, la gestión sectorializada y el control estatal de los órganos urbanísticos, desmunicipalizándose el gobierno metropolitano sin resolver sus principales problemas ${ }^{5}$.

No será, sin embargo, hasta el auge del desarrollismo, impulsado por la planificación, cuando comenzarán a ser preocupantes los principales problemas administrativos derivados de la aglomeración de personas en los cinturones de las ciudades, lo que sucederá en los años sesenta y continuará durante los setenta, como relataba JORDANA DE POZAS ${ }^{6}$. El crecimiento de las áreas metropolitanas de Madrid y Barcelona se traducirá entonces en normas como la Ley de 2 de diciembre de 1963, de creación de la Comisión de Planeamien-

\footnotetext{
${ }^{5}$ Vid. Barrero Rodríguez, $\mathrm{M}^{\mathrm{a}}$ Concepción, Las áreas metropolitanas, Instituto García Oviedo, Civitas, Madrid, 1993, pp. 35 y sigs.

6 Vid. Jordana de Pozas, Luis, «Problemas de las grandes aglomeraciones urbanas desde el punto de vista de la organización administrativa», Estudios de Administración local y general, IEAL, Madrid, 1961.
} 
to y Coordinación del Área Metropolitana de Madrid, y el Decreto-Ley de 24 de agosto de 1974, de creación de la Entidad municipal de Barcelona ${ }^{7}$.

Estas dos leyes representarían estrategias diferenciadas en el tratamiento orgánico de la cuestión, con mayor predominio municipal la segunda, y dependiente del Estado la primera, aunque ambas planteaban el problema del déficit democrático de la respuesta metropolitana, circunstancia que propiciaría, en algunos casos, la reacción autonómica de rechazo a las áreas metropolitanas tras la aprobación de la Constitución de 1978 y la definitiva instauración del régimen democrático ${ }^{8}$.

Así, la creación de las Comunidades Autónomas, nuevos poderes administrativos con competencias supramunicipales, dio lugar, con el tiempo, y una a una, a la supresión o el fracaso de las distintas áreas metropolitanas, comenzando por la Corporación Administrativa Gran Bilbao, en el País Vasco, y continuando, a lo largo del tiempo, con las áreas de Madrid y Barcelona. Muchos de los problemas de estructuración de las áreas metropolitanas obedecen en mi opinión a las reservas mostradas por las Comunidades Autónomas ante organizaciones administrativas que pudieran restarles protagonismo, precisamente en los espacios donde residen la mayoría de sus ciudadanos (y votantes).

Hay que llegar hasta la Ley de Bases de Régimen Local, Ley 7/1985, de 2 de abril, para encontrarse un tratamiento más general de las Áreas metropolitanas, previstas en su artículo 43, precepto que reserva a Ley autonómica su creación («...previa audiencia de la Administración del Estado y de los Ayuntamientos y Diputaciones afectados..., de acuerdo con lo dispuesto en sus respectivos Estatutos»), definiéndolas («....entidades locales integradas por municipios de grandes aglomeraciones urbanas entre cuyos núcleos de población existan vinculaciones económicas y sociales que hagan necesaria la planificación conjunta y la coordinación de determinados servicios y obras»), y estableciendo el contenido necesario de su normativa («...órganos de gobierno y administración, en los que estarán representados todos los municipios integrados en el área; el régimen económico y de funcionamiento, que garantizará la participación de todos los municipios en la toma de decisiones y una justa distribución de las cargas entre ellos; así como los servicios y obras de prestación o realización metropolitana y el procedimiento para su ejecución») ${ }^{9}$.

\footnotetext{
7 Vid. Morell OCAÑA, Luis, «El régimen urbanístico de las grandes ciudades y sus zonas de influencia», Revista de Administración Pública, núm.78, 1976.

8 Vid. Barrero Rodríguez, Ma Concepción, Op. cit, p. 47.

${ }^{9}$ En general, la doctrina se ha pronunciado sobre este precepto en sentido positivo, pero reconociendo la necesidad de su desarrollo por parte de las leyes autonómicas. Vid. BARRERo RodríGuez, Op. cit., p. 34. Rivero Ysern, José Luis, Manual de Derecho local, Civitas, Madrid, 2005. Sosa Wagner, Francisco, Manual de Derecho local, Aranzadi, Pamplona, 2005.
} 
PROBLEMAS ADMINISTRATIVOS EN LOS NUEVOS ESPACIOS METROPOLITANOS

Los sucesivos cambios en la Ley de Bases de Régimen Local no han afectado a la regulación de esta figura. Hay que recordar, en este sentido, que la última reforma importante de la Ley de Bases se produce mediante la llamada Ley de modernización del Gobierno local, en 2003, una norma destinada, por un lado, a retocar aspectos generales del régimen local español (que afectan por tanto a todos los municipios y provincias), y por otro a contemplar disposiciones específicas para los municipios de gran población, las llamadas «grandes ciudades» (aunque se han incluido muchas no tan grandes) ${ }^{10}$.

Recordar esta reforma parece especialmente oportuno ahora, porque la problemática de los nuevos espacios metropolitanos afecta destacadamente a las grandes ciudades, de manera que aquella reforma pudo aprovecharse también para incidir sobre esta materia, pero se limitó a introducir nuevos elementos orgánico-funcionales, sin resolver otros problemas de las grandes ciudades ${ }^{11}$.

Antes, recapitulando las últimas reformas, tuvo lugar el llamado Pacto Local y (en 1999) las modificaciones legislativas derivadas del mismo. Se modificaron entonces muchas normas, hasta la Ley Orgánica del Tribunal Constitucional, y por supuesto también la Ley de Bases, mediante la Ley 11/ 1999, de 21 de abril. Los problemas de las áreas metropolitanas en España, a día de hoy, no son muy distintos, en líneas generales, a los que se planteaban ya en ese momento, así que habría que reconocer también — puesto que voy a hacer hincapié en algunas carencias de la próxima reforma- que en modificaciones anteriores ya pudieron tomarse medidas ${ }^{12}$.

Aunque tal vez hay que plantearse la cuestión de hasta qué punto pudieron entonces las Cortes Generales, y pueden ahora, caso de tramitarse una reforma (o contrarreforma) del régimen local, acometer estos problemas. Parece pertinente la pregunta porque en las actuales circunstancias de desarrollo del Estado Autonómico, y dada la asunción de la competencia exclusiva sobre régimen local por parte de las Comunidades Autónomas (también por la nuestra, Castilla y León, por cierto, justo después de dictar su propia Ley sobre la materia), la solución a los problemas de los nuevos espacios metropolitanos no está, ni quizás debería estar, en manos del Gobierno Central, y sí mucho más del lado de los Autonómicos y Locales.

En fin, más adelante entraré a deslindar lo que creo que es competencia del Estado, y por tanto cabe realizar a través de las reformas subsiguientes

\footnotetext{
10 Vid. Carro Fernández-Valmayor, José Luis (Dir.), Modernización del Gobierno local: estudios sobre la Ley 57/2003, de 16 de diciembre, de medidas para la modernización del gobierno local, Atelier, Barcelona, 2006.

${ }^{11}$ Vid. Merino Estrada, Valentín, «La ordenación del territorio en las grandes ciudades», en Millaruelo Aparicio, José/Orduña Rebollo, Enrique, Ordenación del territorio y Desarrollo sostenible, Ciudad Argentina, Buenos Aires-Madrid, 2004, p. 121, sigs.

12 Vid. Calonge, Antonio/Allué, Alfredo/González Del Teso, Teodosio, El Pacto local de 1999: medidas para el desarrollo del gobierno local, Comares, Granada, 2000.
} 
al Libro Blanco - la próxima Ley Básica del Gobierno y la Administración Local—, y lo que pienso que pueden hacer las Comunidades Autónomas para dar respuesta a la realidad de los nuevos espacios metropolitanos.

\section{El reconocimiento en el Libro blanco para la Reforma del Gobierno local en España de la problemática de las grandes áreas urbanas y su escaso tratamiento en el Borrador de Anteproyecto de Ley Básica del Gobierno y la Administración Local}

Que los problemas de la Administración local en España hoy son bien distintos a los de hace 25 años lo sabemos todos, aunque nos lo recuerda el Libro Blanco con una exposición elocuente de las razones de estos cambios. España ha experimentado afortunadamente grandes transformaciones en este tiempo que sitúan a nuestra sociedad entre las llamadas de bienestar, a pesar de tantas dificultades, mientras que en el momento de la aprobación de nuestra Constitución, estábamos aún en vías de desarrollo. Hoy que nuestras ciudades se asemejan al resto de las europeas, parece necesario un tratamiento de la realidad urbana a la altura de las circunstancias de Europa ${ }^{13}$.

El Libro Blanco se detiene en la realidad de la intermunicipalidad y las grandes áreas urbanas en varios momentos. Respecto de la intermunicipalidad, dice en la página 10 que «Quizás fuera conveniente reivindicar no tanto la supramunicipalidad como la intermunicipalidad, la facultad de los municipios para asociarse en la prestación de servicios o para dar impulso a un proyecto conjunto». En la página 78 se consideran como entidades intermunicipales la provincial, las mancomunidades y las áreas metropolitanas. En las páginas 89 a 92 se defiende la necesidad de evolucionar hacia un «asociacionismo municipal más racional», que contemple nuevas fórmulas de asociacionismo (como las previstas en la Ley Catalana 21/2002), reconociendo por tanto el protagonismo de las Comunidades Autónomas en esta materia, al citar como ejemplo la Ley Catalana 21/2002 y la figura de la Comunidad de municipios. Lo dice el Libro Blanco, en su página 92: «El establecimiento de las diferentes formas de intermunicipalidad y su promoción debería ser objeto de una atención preferente por los gobiernos de las CCAA, que son las que de acuerdo con los municipios afectados pueden diseñar las formas organizativas que más se adecuen a sus respectivos territorios».

Respecto de los espacios metropolitanos, encontramos las siguientes referencias: «...es preciso detenerse con la mayor atención en la articulación de los espacios metropolitanos, espacios complejos donde se impone la co-

\footnotetext{
13 Vid. Rodríguez Álvarez, José Manuel, «Las áreas metropolitanas en Europa: un análisis casual y tipológico», REALA núm. 296-297, 2005.
} 
PROBLEMAS ADMINISTRATIVOS EN LOS NUEVOS ESPACIOS METROPOLITANOS

operación y la coordinación de las distintas administraciones públicas y de las diversas políticas sectoriales, como territorios donde se juega el futuro del país» (p. 11); en la página 78 se dice de las áreas metropolitanas que son una figura poco desarrollada en España, a pesar de responder «... a la necesidad de gestionar los complejos servicios de las aglomeraciones urbanas y mejorar la competitividad de sus ciudades, necesidad cada vez más patente en una sociedad crecientemente urbanizada y donde normalmente las grandes aglomeraciones urbanas desbordan los límites administrativos de la ciudad central, haciendo necesaria la planificación y gestión conjunta o coordinada de los servicios más importantes a escala metropolitana. No puede sorprender que el debate metropolitano constituya en la actualidad uno de los grandes ejes de las políticas locales en todos los países desarrollados: aquí nos encontramos ante un fenómeno de enorme complejidad, que afecta a las zonas más dinámicas de los distintos países, y que por ello requiere una atención prioritaria por parte de los poderes públicos».

En las páginas 92 a 94 se detiene el libro en el futuro de las áreas metropolitanas, y de otras figuras como los convenios metropolitanos, reconociendo que en España este fenómeno no se ha abordado adecuadamente y haciendo la siguiente consideración: «Las áreas metropolitanas deben ser una forma específica de intermunicipalidad estratégica para el desarrollo de los territorios metropolitanos...La variedad de modelos hace que no exista una receta general sobre cómo deben organizarse las áreas metropolitanas españolas. Sí parece, en cambio, que se puedan señalar los factores críticos de cara a la utilidad de estos gobiernos. Entre otros, señalaríamos la necesidad de que haya voluntad de cooperación entre los municipios implicados, la aplicación de mecanismos de solidaridad territorial, la definición clara y precisa de unas competencias acompañadas de recursos financieros suficientes, la eficacia y la eficiencia en la respuesta a los problemas y retos del área, y un liderazgo institucional o territorial por el gobierno impulsor de la institución».

A continuación, se apunta hacia una figura específicamente pensada para responder a necesidades funcionales (de servicios y políticas públicas): los convenios metropolitanos ( Las grandes conurbaciones, singularmente, exigen a la vez la coordinación de todos los actores territoriales que inciden en ellas, y la articulación de todas las políticas sectoriales que las afectan, para lograr las sinergias necesarias y avanzar por la senda de la cohesión territorial y social. A estos efectos, se considera que procede la introducción en la legislación básica de régimen local de los «convenios metropolitanos», como instrumentos voluntarios flexibles de colaboración entre el Estado, las comunidades autónomas y las áreas metropolitanas institucionales —o los municipios de las áreas metropolitanas funcionales-, con la finalidad de desarrollar un proyecto metropolitano común mediante la planificación de las inversiones y la coordinación de las grandes políticas públicas que afectan a la metrópoli: planeamiento urbanístico, grandes infraestructuras de transporte, movilidad, 
vivienda, medio ambiente (incluyendo el ciclo hidráulico y de los residuos), seguridad ciudadana, desarrollo económico local...»). En estos convenios, se dice también, podrían incorporarse actores institucionales y sociales relevantes (universidades, cámaras de comercio, sindicatos, patronales).

Resumiendo los contenidos del Libro Blanco sobre esta materia, hasta aquí expuestos, podemos decir que se ofrece un diagnóstico y una solución práctica. El diagnóstico demuestra la necesidad de mucha mayor intermunicipalidad en el régimen local español, especialmente en los nuevos espacios metropolitanos. La solución práctica ofrecida es la de los «convenios metropolitanos», que serían una variedad de los convenios administrativos, con la peculiaridad (característica, por ejemplo, de los consorcios locales) de poder incorporar tanto protagonistas públicos como privados. No se explica en detalle cuáles serían las características peculiares y diferenciadoras de estos convenios - que se propone incorporar en la legislación básica - respecto de las herramientas de colaboración interadministrativa previstas en estos momentos en la normativa básica, tanto de régimen jurídico de las Administraciones públicas, como de régimen local.

Creo que una de las principales tareas a desarrollar por los administrativistas, teniendo muy en cuenta lo que dicen los geógrafos, es intentar ahondar en las propuestas del Libro Blanco, analizando las herramientas disponibles hoy para responder a la problemática metropolitana, y las que podrían contemplarse adicionalmente en el futuro, planteando también quién puede tener la competencia para incorporarlas (el Estado, la Comunidad Autónoma, los propios entes locales).

También creo que no cabe duda de la necesidad de que el Derecho ofrezca soluciones institucionales a esta problemática, una necesidad de la que, sin embargo, el Borrador de Anteproyecto de Ley Básica del Gobierno y la Administración Local no parece preocuparse demasiado, porque entre sus seis títulos, cinco disposiciones adicionales, disposiciones transitorias, finales y derogatoria (en la versión de 22 de noviembre de 2005) no encontramos ninguna referencia específica a las áreas metropolitanas.

Así, aunque el artículo 6 del Borrador prevé la creación de las entidades locales por las Comunidades Autónomas, no detalla cuáles pueden ser estas entidades, en cuya creación se han de respetar los principios de autonomía de los entes locales necesarios, representación de todos los municipios integrados, y eficiencia y economía para evitar duplicidades competenciales. Desaparece en esta nueva Ley el artículo 43 de la actual Ley de Bases, dedicado a las áreas metropolitanas, de manera que todo su régimen jurídico, sin limitación alguna por parte del legislador estatal, quedaría en manos de las asambleas parlamentarias autonómicas.

Esta solución parece correcta, hasta cierto punto, teniendo en cuenta el actual reparto de competencias en materia de régimen local, que además in- 
PROBLEMAS ADMINISTRATIVOS EN LOS NUEVOS ESPACIOS METROPOLITANOS

terpreta restringiendo las competencias el Estado en la fijación de las bases el Libro Blanco, como por otra parte se observa en otros proyectos, como el Estatuto Básico del empleado público, que ofrece la misma visión reductora de las bases, dado su carácter versátil y en cierto modo maleable. Pero sorprende teniendo en cuenta la importancia que concede el mismo Libro Blanco, como hemos visto, a la problemática de la intermunicipalidad, especialmente en los grandes núcleos urbanos, así que quizás hubiera sido oportuno incluir en el Anteproyecto mayores referencias al instrumental de posibles soluciones institucionales a la problemática de las áreas metropolitanas, tan convenientes desde un punto de vista económico, social e incluso ambiental, dados los efectos que el galopante desarrollo urbanístico de las grandes ciudades tiene sobre la vida de las personas ${ }^{14}$.

\section{El Derecho como herramienta de solución de problemas en los nuevos espacios metropolitanos: experiencias autonómicas comparadas y otras soluciones institucionales que la normativa de régimen local podría ofrecer}

\section{A) La necesidad de la respuesta autonómica a la problemática metropolitana y su corto alcance en el panorama comparado}

Resulta sin duda muy positivo que en un análisis sobre la posible reforma del Gobierno local en España - el Libro Blanco - se enuncien diagnósticos, pero no hay que perder de vista que el Derecho lo que tiene que ofrecer son soluciones institucionales adaptadas a los principales problemas, también a los específicos de las áreas metropolitanas ${ }^{15}$. Y, como acabamos de ver, si atendemos al Borrador de Anteproyecto de Ley Básica del Gobierno y la Administración Local, la cuestión de la organización supramunicipal, no muy bien tratada en general en nuestro Derecho ${ }^{16}$, queda totalmente en manos de las Comunidades Autónomas, que también deben afrontar el fenómeno metropolitano, un fenómeno que en sí mismo requiere soluciones institucionales y organizativas peculiares, herramientas apropiadas para dar respuesta a las nuevas necesidades que suscita ${ }^{17}$.

Los problemas que plantea del desarrollo de nuestras ciudades, desde el punto de vista de la prestación de los servicios y la calidad de vida de los ciu-

14 Vid. Sánchez Blanco, Ángel, Organización intermunicipal, Iustel, Madrid, 2006.

15 Vid. Clavero Arévalo, Manuel, «Prólogo», a Barrero Rodríguez, Ma Concepción, Las áreas metropolitanas, Instituto García Oviedo/Civitas, 1993.

16 Vid. Esteve Pardo, José, Organización supramunicipal, Civitas, Madrid, 1991. FonT i Llovet, Tomás, «Perspectivas de organización supramunicipal», Revista de Estudios de la Administración Local, núm. 226, 1985.

17 Vid. Rodríguez Álvarez, J.M, «La política sobre las grandes ciudades y Áreas Metropolitanas de España o el temor a la diversidad», Gestión y Análisis de Políticas Públicas, núm. 24, 2002. 
dadanos, son bastante graves. Por ello la ordenación del territorio y el urbanismo, por ejemplo, no pueden ser enfocados en los grandes espacios metropolitanos de la misma forma que en los municipios sin este carácter. Determinadas decisiones, por su incidencia supramunicipal, no pueden ser dejadas simplemente en manos de los Ayuntamientos, aisladamente considerados, ni solventadas con meros controles ejercidos por la Comunidad Autónoma, sin participación directa de otros municipios potencialmente afectados ${ }^{18}$.

Todo esto es bien sabido, y se encuentra reconocido en el tratamiento del fenómeno metropolitano en el Derecho comparado de otros países, en el que no entraré ahora, pero que han analizado antes otros autores ${ }^{19}$. El Derecho español, en cambio, más allá de las mínimas referencias de la Ley de Bases, que ahora desaparecerán, no ofrece apenas respuestas específicas a la problemática metropolitana. Un análisis del Derecho autonómico comparado nos lo puede corroborar, pues aunque se encuentran algunas soluciones institucionales de referencia en las normas de otras Comunidades Autónomas, que podrían ser trasladadas a Castilla y León, en general no se puede decir que las áreas metropolitanas hayan sido potenciadas en nuestro país ${ }^{20}$.

El fracaso de la figura en nuestro panorama local se ha achacado a la falta de acuerdo suficiente entre todas las entidades que tendrían que integrarse en el área metropolitana, así como a experiencias previas (COPLACO, Corporación Administrativa del Gran Bilbao, Corporación Administrativa del Gran Valencia) destacadas por un excesivo centralismo, ya sea de la Administración central, ya del principal municipio de referencia. Sea como fuere, en el Estado de las Autonomías tampoco han tenido éxito como solución institucional, a pesar de que algunas Comunidades Autónomas hayan recogido menciones a las áreas metropolitanas en sus Estatutos de Autonomía, como es el caso de Asturias, Castilla-La Mancha, Cataluña, Galicia, Comunidad Valenciana o La Rioja ${ }^{21}$.

Buenos ejemplos de esta situación se encuentran en Andalucía, donde aunque se reconoció algún papel a la figura de las áreas metropolitanas, no han terminado de desarrollarse organizativamente, ni para el caso de Sevilla, ni para el de Málaga ${ }^{22}$. O en Cataluña, donde fue muy criticada la su-

\footnotetext{
${ }^{18} \mathrm{Vid}$. Merino Estrada, Valentin, «La ordenación del territorio en las grandes ciudades», en Millaeruelo Aparicio, José/Orduña Rebollo, Enrique (Coordinadores), Ordenación del territorio y desarrollo sostenible, Ciudad Argentina, Buenos Aires-Madrid, 2004.

${ }^{19}$ Vid. Cuchillo Foix, Montserrat/Morate, Francesc, Organización y funcionamiento de las áreas metropolitanas, INAP, Madrid, 1990. RodRíGuez Álvarez, José Manuel, «Las áreas metropolitanas en Europa: un análisis casual y tipológico», REALA núm. 296-297, 2005.

${ }^{20}$ Vid. SÁnchez Blanco, Ángel, Organización intermunicipal, Iustel, Madrid, 2006.

${ }^{21}$ Vid. SÁnCHez Blanco, Op. cit., p. 26.

22 Vid. Morillo Velarde, José Ignacio, «Las competencias de las áreas metropolitanas de Andalucía», en Administración de Andalucía, núm. 28, 1996.
} 
PROBLEMAS ADMINISTRATIVOS EN LOS NUEVOS ESPACIOS METROPOLITANOS

presión por razones políticas del área metropolitana de Barcelona, con la solución alternativa de las áreas metropolitanas funcionales, como las entidades metropolitanas de transporte y la entidad metropolitana de tratamiento de residuos ${ }^{23}$.

En Valencia, la Ley 2/2001, de 11 de mayo, de creación y gestión de áreas metropolitanas de la Comunidad Valenciana, ofrece quizás el marco normativo más completo del panorama comparado, pues piensa en dar respuesta a la situación de varios grandes municipios, no de un solo área, como la mayoría de las normas precedentes en otras Comunidades, y en la evolución de nuestro régimen local. Pero lejos de mantener las áreas ya existentes, como el Consell Metropolitá de 1’Horta, creado en 1986, lo descarta (el Área Metropolitana de 1'Horta fue suprimida por Ley 8/1999), planteando como alternativa, al igual que en Cataluña, entidades metropolitanas funcionales (Entidad Metropolitana de Servicios Hidráulicos, Entidad Metropolitana para el Tratamiento de Residuos). La Ley de Ordenación del Transporte Metropolitano de Valencia ahondará en esta opción funcional, renunciando a los proyectos más ambiciosos de soluciones organizativas para la solución integral de los problemas ${ }^{24}$.

Los casos catalán y valenciano demuestran a las claras la renuncia de las Comunidades Autónomas a crear organizaciones personificadas que agrupen a los municipios para dar respuesta a la problemática metropolitana, salvo para servicios concretos, atendiendo muy específicamente los asuntos más perentorios. Funcionan de este modo las soluciones institucionales previstas a modo de mancomunidades, sin acometer la necesaria coordinación administrativa de modo integral.

\section{B) Soluciones institucionales que la normativa de régimen local podría ofrecer: tipología instrumental metropolitana y competencias para su regulación}

Probablemente la falta de voluntad política para optar por soluciones integrales sea un factor importante, pero quizás también la alternativa de las áreas metropolitanas personificadas plantee los problemas de la multiplicación de los niveles administrativos, problemas similares a los que se observan en las alternativas comarcalizadoras, dada la constitucionalización de la provincia, y los efectos negativos de superponer nuevos instancias decisorias. De ahí que sea necesario repasar todas las soluciones institucionales posibles, alternativas a las nuevas organizaciones públicas, para afrontar los problemas planteados.

\footnotetext{
23 Vid. Martín Mateo, Ramón, «La reorganización de la Administración metropolitana de Barcelona», en Muñoz Machado, Santiago, Tratado de Derecho Municipal, Civitas, Madrid, 1986.
}

${ }^{24}$ SÁnchez Blanco es especialmente crítico con esta opción para el caso andaluz, Op. cit., p. 156. 
En la tipología de soluciones institucionales pueden describirse básicamente cuatro posibilidades: 1 . Creación de una estructura organizativa con competencias de resolución de los problemas, sustituyendo a los municipios incorporados en los procesos de toma de decisiones. 2. Creación de órganos de colaboración, personificados (en distintas formas, por ejemplo, consorcios), o no, para cuestiones puntuales. 3. Convenios para cuestiones específicas. 4. Participación de los municipios afectados por las decisiones de programación y planificación de otros entes en los procedimientos para su adopción. Estas cuatro opciones representan, de más a menos, el grado de imbricación de los distintos municipios en la toma de decisiones y en el desarrollo de las políticas sobre las cuestiones que les afectan a todos.

En la solución institucional máxima de creación de una estructura organizativa alternativa a los municipios, la naturaleza y posibles funciones de las áreas metropolitanas dejan bastante margen decisorio a sus creadores (los legisladores autonómicos, previa audiencia de la Administración del Estado y de los Ayuntamientos y Diputaciones afectados) a la hora de definir las tareas que se les encomiendan, así como su estructura organizativa. Para explicarlo en concreto, es la Ley de creación la que define para qué sirve el área metropolitana (servicios y obras), cómo se financia (distribución justa) y cómo se gobierna (con participación de todos los municipios en la toma de decisiones). Está bastante abierto lo que pueden hacer (la expresión servicios y obras tradicionalmente se equipara al «giro o tráfico» administrativo), con qué recursos y con qué estructura organizativa (no todos los municipios deben necesariamente tener la misma representación, sino que pueden estar representados en función de su peso específico poblacional, o utilizando varios criterios alternativos).

Aquí tengo que decir que no estoy totalmente de acuerdo con la interpretación que ofrece José Luis RIVERo YSERN en su Manual de Derecho local, cuando dice que la ley autonómica «...no es en absoluto libre a la hora de conformar la organización de la Entidad, sino que debe respetar el principio democrático, de tal modo que la representación de los municipios en los órganos de gobierno de la entidad deben estar en función exclusivamente del número de habitantes de cada municipio» ${ }^{25}$. Esto puede ser un principio, dado que la doctrina también ha destacado los problemas de conflicto con la autonomía local que podrían derivarse del desacuerdo de uno de los municipios que hubiera de integrarse en el área metropolitana, caso de no aceptar su integración o la forma de ésta, por ejemplo por no considerarse bien representado. Pero las traducciones del principio democrático en términos de participación pueden ser a mi juicio diversas.

Las problemas planteados por el equilibrio de representación en los órganos de gobierno serían sobre todo políticos, pero en un análisis riguroso de nuestro

${ }^{25}$ Rivero YSERn, José Luis, Manual de Derecho local, cit., p. 
PROBLEMAS ADMINISTRATIVOS EN LOS NUEVOS ESPACIOS METROPOLITANOS

régimen local, el límite definido al legislador autonómico sería el núcleo duro de la autonomía local (en su condición de garantía institucional), de manera que no podría vaciarse materialmente esta autonomía mediante la creación de un área metropolitana, asignando al nuevo ente, por ejemplo, la mayoría (o las principales) de las competencias o servicios municipales. Una operación en este sentido sería sin duda contraria a la Constitución, pero entre vaciar la autonomía municipal y asignar la gestión de obras y servicios a una entidad supramunicipal hay todo un margen de maniobra que permite abordar un gran número de políticas que interesan a todos los municipios de un determinado área desde la estructura metropolitana.

La segunda solución institucional serían los órganos de colaboración, sin personalidad jurídica, lo que les resta capacidad de actuación, o con ella, por ejemplo con la forma de consorcios o de entidades metropolitanas funcionales, como las que han venido funcionando en Cataluña o Valencia. También podría explorarse la posibilidad de constituir, para problemas muy concretos o proyectos comunes Uniones temporales intermunicipales o Alianzas Municipales Estratégicas. Determinados proyectos o políticas públicas requieren una colaboración continua e institucionalizada entre los municipios (eventualmente, también otras Administraciones públicas e incluso sujetos privados). El área metropolitana, en tanto en cuanto solución institucional con vocación de permanencia y verdadera sustitución del papel de los municipios, restándoles el protagonismo que legítimamente les corresponde, plantea problemas. El convenio probablemente se queda demasiado corto, porque sólo resuelve problemas muy específicos, o al menos está pensado para este fin. Así que en ocasiones pueden ser necesarias soluciones a caballo entre las áreas metropolitanas, entendidas como verdaderas entidades locales, y los convenios, acuerdos episódicos en un proceso de relación interadministrativa.

La tercera solución serían los convenios administrativos, en concreto, los convenios metropolitanos, propuestos por el Libro Blanco, que sin embargo presentan tanto ventajas como inconvenientes. Presentan la ventaja de presumir la voluntad de las partes, que difícilmente puede forzarse, respecto de la integración forzosa mediante Ley en el área metropolitana. En nuestra Comunidad Autónoma tenemos ejemplos de conflictos con municipios que no aceptan la ubicación de determinadas instalaciones de las que se beneficia una gran área urbana (caso del vertedero de Gomecello, en Salamanca), o incluso toda la industria de la región (caso Santovenia). El conflicto en defensa de la autonomía local permite que estos contenciosos terminen en el Tribunal Constitucional, siendo el litigio una forma indeseable de resolución de las desavenencias interadministrativas.

La desventaja de estos convenios sería, a mi modo de ver, su mera condición de tales, pues si es cierto que caben los convenios abiertos, sin un clausulado cerrado, esta figura parece estar pensada para realizaciones muy concretas, sin un soporte institucional estable que permita (como podría ha- 
cerlo un consorcio, o la creación de cualquier entidad personificada a la que se asignaran las tareas conjuntas) ir más allá de un solo servicio o una sola obra. Sus ventajas y desventajas, y aspectos de régimen jurídico, han sido tratados por la doctrina ${ }^{26}$.

Por último, la participación en los procesos de toma de decisiones parece más problemática, aunque se pueda reconocer en las decisiones de la Administración del Estado, o de la Comunidad Autónoma, puede ser más difícil que un municipio intervenga en las decisiones de otro, salvo por la controvertida vía del contencioso-administrativo ${ }^{27}$.

En la elección de las opciones, desde mi punto de vista, se debe preferir el carácter voluntario, evitando la propuesta de soluciones más tajantes con la autonomía municipal para abordar la problemática de las áreas metropolitanas, soluciones de corte claramente tecnocrático, pero no muy consideradas con la legitimidad democrática de las corporaciones, por ejemplo, la anexión. A mi juicio, la legitimidad democrática debe ser siempre tenida en cuenta, siendo necesario armonizar la respuesta a los intereses supramunicipales con la relación existente entre los ciudadanos y sus representantes más próximos (alcaldes y concejales). Pienso que en nuestro marco constitucional no parece adecuado ni conveniente «desmunicipalizar» el gobierno metropolitano. Y las soluciones alternativas, del estilo de la fusión de municipios, parecen excesivamente traumáticas, aunque de no adoptarse otras decisiones pueden terminar siendo inevitables ${ }^{28}$.

¿Pero quién puede o debe regular todas estas figuras? Aquí corresponde entrar en la cuestión de la distribución de competencias. A la vista del Libro Blanco sobre la reforma del Gobierno local en España, pareciera que el legislador estatal tiene algo que decir sobre las mismas, pero el Borrador de Anteproyecto de Ley Básica del Gobierno y la Administración Local elude hacerlo. Desde mi punto de vista, al Estado le corresponde establecer las modalidades básicas de relación interadministrativa, abrir las figuras de los convenios, los consorcios, las sociedades mixtas administrativas, incluso para que también los entes locales puedan utilizarlas. Esto en virtud del artículo 149.1.18 de la Constitución.

Al legislador autonómico le corresponde la principal competencia sobre régimen local, luego debería desarrollar y adaptar para sus propias peculiaridades las distintas fórmulas de solución institucional metropolitana, bajo

\footnotetext{
26 Vid. Martín Huerta, Pablo, Los convenios interadministrativos, INAP, Madrid, 2000.

27 Valentín Merino llega a plantear que la «gran ciudad» pueda vetar determinadas decisiones: «Lo que sí resulta posible y aconsejable es que las comunidades autónomas, en instrumentos de ordenación específicos para las áreas urbanas, otorguen poderes relevantes a la ciudad central o gran ciudad. Poderes de veto para evitar consecuencias no queridas o injustas...», Op. cit., p. 136.

${ }^{28}$ Vid. RodríGuez GonZÁlez, R., Territorio y gobierno local en España. Un planteamiento de reestructuración por fusión como realidad necesaria, Civitas, Madrid, 2005.
} 
PROBLEMAS ADMINISTRATIVOS EN LOS NUEVOS ESPACIOS METROPOLITANOS

la denominación de convenios, o de consorcios, o de agrupaciones o alianzas, figuras de colaboración específicamente pensadas para la problemática de los grandes espacios urbanos. Nada incompatible con la legislación básica, que tampoco va a descender a regular todas y cada una de las posibles formas de articulación de la colaboración intermunicipal a nivel metropolitano.

\section{El caso de Castilla y León: la escasez de la respuesta normativa en la Ley de Régimen Local y las insuficiencias de otras previsiones normativas (Ley de Ordenación del Territorio y Directrices de Ordenación, Ley del Transporte Urbano y Metropolitano)}

Castilla y León, a diferencia de otras Comunidades, no ha reconocido la necesidad de una respuesta específica a la realidad metropolitana. El Estatuto de Autonomía de Castilla y León y la Ley 1/1998, de Régimen Local de nuestra Comunidad Autónoma, apenas contienen referencias a esta problemática. Y en el resto de las principales normas que deberían contemplarla, como las referidas al urbanismo y la ordenación del territorio, tampoco se trata en profundidad.

El artículo 45 de la Ley de Régimen Local, se limita a establecer lo siguiente: «1. Aquellos municipios entre cuyos núcleos de población existan vinculaciones económicas, sociales y urbanas que hagan necesaria una actuación de alcance supramunicipal podrán ser integrados en una entidad metropolitana para la planificación conjunta y la gestión coordinada de determinadas obras y servicios. 2. La creación, modificación o supresión de entidades metropolitanas se llevará a cabo mediante una Ley específica para cada supuesto, previa audiencia de la Administración del Estado y de los Ayuntamientos y Diputaciones Provinciales interesadas. 3. La iniciativa para la creación de la entidad metropolitana podrá partir de los municipios interesados y, en este caso, se requerirá acuerdo adoptado con el voto favorable de la mayoría absoluta del número legal de miembros de cada corporación. 4. En las entidades metropolitanas existirá un Consejo en el que estarán representados todos los municipios integrados, con la finalidad de decidir sobre los servicios de interés común».

Apenas añade nada este precepto respecto del 43 de la Ley de Bases, antes analizado, pues su apartado segundo reproduce el contenido del 43.1 LBRL, su apartado primero reproduce el 43.2 LBRL, y sólo los apartados tercero y cuarto contemplan un régimen añadido al básico: el tercero para contemplar un procedimiento que no es el único posible para la constitución del área, pues cabe también la integración de municipios sin su iniciativa; y el cuarto para decir que existirá un Consejo, que es uno de los órganos de gobierno a los que se refiere el 43.3 LBRL, un precepto que detalla muchos más aspectos 
de lo que debe ser el estatuto de las áreas metropolitanas. Luego la regulación autonómica de Castilla y León es bastante escasa, y se refiere sólo a una de las posibles soluciones institucionales para afrontar la problemática metropolitana, que es la creación de una estructura organizativa ad hoc, no siendo, como hemos explicado, esta solución la única posible ni siempre la más recomendable.

En la Ley de Ordenación del Territorio de Castilla y León, Ley 10/1998, de 5 de diciembre, además de los principios del artículo 2, podrían destacarse en relación a esta problemática los artículos 14, sobre las Directrices de ámbito subregional, y el 27, sobre la coordinación administrativa. También son destacables los mismos preceptos sobre la coordinación administrativa, más desarrollados en la Ley de Urbanismo, Ley 5/1999, de 8 de abril, reformada por la Ley 19/2002, de 10 de julio. En esta norma se dedica todo un Título, el V, a la Organización y Coordinación administrativas, destacando los artículos 134, sobre formas de colaboración (apartado 1), el 138, sobre las Comisiones Territoriales, y el 140, con varias llamadas a la coordinación que demuestran su necesidad (también lo difícil de su realización).

Siendo estos dos textos importantes, la Ley de Transporte Urbano y Metropolitano, Ley 15/2002, de 28 de noviembre, es quizás la norma que más directamente se ocupa de la problemática que nos interesa. Pero lejos de contemplar un instrumental amplio de colaboración interadministativa, se limita a regular en su Título III algunos modos de coordinación. Se contempla la posibilidad de la creación de una entidad metropolitana, en su artículo 18.1.a), pero junto a ella sólo se prevén los planes coordinados de explotación, principal respuesta a «las dificultades que se plantean en aglomeraciones urbanas con intensas relaciones intermunicipales».

Las Directrices de Ordenación del Territorio de ámbito subregional para Valladolid y su entorno, aprobadas mediante Decreto 206/2001, de 2 de agosto, representan seguramente, por debajo de las leyes, la principal norma que debe ocuparse principal área metropolitana en Castilla y León. Y lo hacen hasta cierto punto, pues reconocen que estamos, hace ya cinco años, ante un «área metropolitana en formación», y son conscientes de los conflictos intermunicipales y las dificultades para los ciudadanos que se derivan de esta circunstancia.

Estas normas intentan controlar los efectos del crecimiento del área metropolitana sobre el medio ambiente y el patrimonio histórico-artístico, así como evitar una excesiva aglomeración urbana en el entorno de Valladolid, pero los resultados parecen desmentir sus objetivos declarados, pues es perceptible el crecimiento descontrolado de urbanizaciones sin una adecuada dotación de servicios. 
PROBLEMAS ADMINISTRATIVOS EN LOS NUEVOS ESPACIOS METROPOLITANOS

\section{Crítica constructiva ante las perspectivas de nueva Ley Básica de la Administración y el Gobierno local y la reforma de los Estatutos de Autonomía: La necesidad, en un medio plazo, de reformar la Ley de Régimen local de Castilla y León}

Un párrafo de la presentación del Libro Blanco realiza la siguiente consideración: «Los gobiernos locales tienen plena conciencia de que no basta la tradicional ventaja comparativa del comercio internacional, lo que ubica a un territorio en el mapa de la globalización no es la posesión de un recurso escaso ni una situación geoestratégica de privilegio, lo que verdaderamente evita la globalización por la puerta trasera es la ventaja cooperativa, el liderazgo político del gobierno local para que actores públicos y privados cobren sentido de sus interdependencias y formen una red capaz de hacer competitivo el territorio. Es la calidad de las interacciones entre actores el mayor activo institucional del que una ciudad puede disponer».

La oportunidad de estas reflexiones es indiscutible, pero al reconocer el propio Libro Blanco la necesidad de restringir el alcance de las bases sobre el régimen local, dadas las actuales tendencias de evolución del Estado de las Autonomías, así como el escenario político de la presente legislatura, el protagonismo en la previsión de este tipo de herramientas jurídicas va a pasar, en mi opinión, al legislador autonómico. Aunque como he dicho quizás el legislador estatal debería ofrecer algunas pautas para el desarrollo del instrumental de soluciones, no tan complejas, que requieren las áreas metropolitanas, estas soluciones tendrán que venir, si se mantiene la actual redacción del Borrador de Anteproyecto de Ley Básica del Gobierno y la Administración Local, del legislador autonómico.

En estas circunstancias, los obstáculos constitucionales que se le plantean al legislador autonómico para desarrollar su competencia en la materia son muy pocos, reduciéndose prácticamente al respeto de la autonomía local, que ahora se encuentra protegida incluso ante el Tribunal Constitucional, aunque sólo en casos extremos podría ser vulnerada por la vía de regulación legal de las áreas metropolitanas. Las intervenciones que pueden dar lugar a un «conflicto en defensa de la autonomía local» pueden ser más bien las propias de leyes-acto o leyes-medida, como por ejemplo la aprobada por las Cortes de Castilla y León en relación al vertedero de residuos industriales de Santovenia de Pisuerga (Valladolid), una verdadera Ley de validación.

Ahora bien, no está de más el refuerzo normativo de las competencias autonómicas y sus decisiones sobre esta cuestión. Por ello se percibe cada vez más claramente la necesidad de la reforma de la Ley de Régimen Local, ante la falta de previsiones suficientes sobre las áreas metropolitanas en este texto. Hay que recordar que la Ley de Régimen Local de Castilla y León se dictó, vuelvo a insistir, antes de asumir mediante la reforma de nuestro Es- 
tatuto de Autonomía, la competencia exclusiva sobre esta materia. Y esta circunstancia queda a mi modo de ver reflejada en el autorestringido alcance de sus contenidos ${ }^{29}$.

La Ley de Régimen Local de Castilla y León apenas se refiere a las áreas metropolitanas, como hemos visto, limitándose en sus previsiones sobre la intermunicipalidad a contemplar la figura de las Mancomunidades de interés comunitario, estableciendo para las mismas líneas especiales de financiación y ciertas ventajas, cuyo desarrollo no se ha producido. Pues bien, en una futura reforma de la Ley de Régimen Local de Castilla y León, aprovechando la oportunidad que ofrece el Pacto Local, podrían preverse como figuras de organización intermunicipal añadidas los acuerdos intermunicipales y los Consorcios, a los que por cierto hacía referencia en su Discurso de investidura el Presidente Juan Vicente HERRERA, planteando potenciarlos como figura de colaboración entre entidades locales, y con la Junta de Castilla y León.

En fin, desde mi punto de vista, por lo expuesto, no puede esperarse demasiado para llevar a cabo una reforma de la Ley de Régimen Local de esta Comunidad Autónoma. Por supuesto, la decisión corresponde a las instituciones de gobierno y a las Cortes de Castilla y León, pero estos días que vuelve a hablarse del Pacto Local (en el nivel autonómico), con las consecuencias que tendrá en la reasignación de competencias, parece oportuno también recordar que hay numerosos aspectos del régimen local que podrían ser regulados por Derecho autonómico y que, de momento, siguen rigiéndose por el Derecho del Estado (que es supletorio en todo lo no considerado básico).

Probablemente es un poco tarde para incorporar nuevos elementos en el Pacto Local, pero como tal vez este Acuerdo active la reforma legislativa indicada, podría aprovecharse la oportunidad para prever, además de las herramientas específicas, que son básicamente las mismas previstas en la legislación del Estado en general para las relaciones interadministrativas, instrumentos de incentivo y apoyo al tratamiento conjunto de problemas característicos de estos nuevos espacios metropolitanos, así tanto líneas de financiación prioritarias como apoyo de todo tipo desde la Comunidad Autónoma.

Estas medidas son más necesarias en el contorno de las grandes áreas urbanas, donde se deben facilitar las Alianzas Estratégicas Municipales entre los gobiernos de las grandes ciudades y los municipios de su entorno, alianzas no necesariamente centradas en la prestación conjunta de servicios, sino en la realización de lo que también se llaman, en la terminología clásica, actividades, y en la programación y planificación de su propio crecimiento,

\footnotetext{
${ }^{29}$ Vid. Rivero Ortega, Ricardo, «Régimen local de Castilla y León: Estudio de la Ley 1/1998, de 4 de junio», REALA, núm. 277, 1998.
} 
PROBLEMAS ADMINISTRATIVOS EN LOS NUEVOS ESPACIOS METROPOLITANOS

con el fin de evitar los costes en términos económicos y las pérdidas de calidad de vida por la falta de coordinación ${ }^{30}$.

30 «Sobre los vecinos metropolitanos se proyectan los directos efectos de lo que con acierto, ha sido calificado como «los costes de las no áreas metropolitanas», traducido en hipertrofia institucional, descoordinación de actuaciones públicas, sectorialización de políticas territoriales, pérdida de recursos financieros, neutralización de competencias municipales, carencia de respuestas específicas e instrumentalización de los intereses vecinales y municipales por la informe ciudad cabecera», SÁNCHEZ BLANCO, Ángel, Organización intermunicipal, cit., p. 90. 